\title{
Sinomenine hydrochloride inhibits breast cancer metastasis by attenuating inflammation-related epithelial-mesenchymal transition and cancer stemness
}

\author{
Xiao Li ${ }^{1}$, Pingping Li ${ }^{2}$, Chao Liu ${ }^{3}$, Yu Ren ${ }^{1}$, Xiaojiang Tang ${ }^{1}$, Ke Wang ${ }^{1}$, Jianjun He ${ }^{1}$ \\ ${ }^{1}$ Department of Breast Surgery, First Affiliated Hospital of Xi'an Jiaotong University, Xi'an 710061, P.R. China \\ ${ }^{2}$ Translational Medical Center, First Affiliated Hospital of Xi'an Jiaotong University, Xi'an 710061, P.R. China \\ ${ }^{3}$ Department of Vascular Surgery, First Affiliated Hospital of Xi'an Jiaotong University, Xi'an 710061, P.R. China \\ Correspondence to: Jianjun He, email: chinahjj@163.com \\ Ke Wang, email: 979915080@qq.com
}

Keywords: sinomenine hydrochloride, breast cancer, metastasis, EMT, CSC

Received: July 04, 2016

Accepted: January 03, 2017

Published: January 10, 2017

\section{ABSTRACT}

Sinomenine hydrochloride (SH) has been investigated for its anti-tumor growth effect. We have previously reported that $\mathrm{SH}$ inhibited breast cancer cell proliferation via MAPKs signaling. However, whether SH could inhibit tumor metastasis has not been fully explored. In this study, we found that SH suppressed the metastasis potential of breast cancer cells. The wound healing and transwell assays showed that SH inhibited the migration and invasion ability of both 4T1 and MDA-MB-231 breast cancer cells. The orthotopic mouse model of 4T1 and the experimental mouse model of MDA-MB231-luc (MDA-MB-231 cell line expressing firefly luciferase) demonstrated that SH treatment inhibited breast cancer metastasis by inhibiting epithelial-mesenchymal transition (EMT) and cancer stem cell (CSC) properties without obvious hepatotoxicity and renal toxicity. We also found that SH decreased spleen volume and weight in both mouse models, especially in the 4T1 mouse model. IL-6, a strong inflammatory factor causing EMT, was remarkably reduced. Overall, this anti-metastasis effect of SH could be possibly caused by attenuating inflammatory reaction, which led to inhibition of EMT and CSC characteristics of breast cancer cells. This study, together with our previous one, provides more evidence of $\mathrm{SH}$ as a potential drug for breast cancer therapy.

\section{INTRODUCTION}

Sinomenine (Supplementary Figure 1A) is an abstract isolated from the traditional Chinese herb Sinomenium acutum Rehd. et Wils. (Fam. Menispermaceae). Previous studies have reported the pharmacological effects of sinomenine, including antiarthritis effect [1], anti-inflammatory [2], anti-cancer effect [3] and so on. Recently, the anti-proliferation and anti-cancer effects of sinomenine have drawn considerable attention. Sinomenine inhibited proliferation and induces apoptosis of NCI-H460 cells in a dose-dependent manner through the mitochondrial pathway [4]. Lu et al. found that sinomenine increased $\mathrm{p} 21$, decreased the Bcl-2/Bax ratio, promoted the release of Cytochrome $\mathrm{c}$ and $\mathrm{Omi} /$ HtrA2 from the mitochondria into the cytoplasm and induced the cleavage of caspase-3 and -9 [3].Our previous study also showed that sinomenine hydrochloride (SH) (Supplementary Figure 1B), a hydrochloride chemical form of sinomenine which is water soluble, arrested cell population at G1 phase, caused cell apoptosis and induced ATM/ATR-Chk1/Chk2-mediated DNA damage in breast cancer cells through regulation of MAPKs pathways [5]. During our study of the anti-proliferation effect of SH [5], we also found that SH could inhibit the invasion and metastasis ability of breast cancer cells. However, there is no study fully investigated the anti-invasion and anti-metastasis effects of SH on breast cancer cells and explored the potential mechanisms. So we carried out experiments to explain the anti-invasion and antimetastasis effect of SH on breast cancer cells.

Breast cancer is one of the most common malignant diseases in western women with an estimated rate of $29 \%$ of all the new cancers in women in 2016 [6]. According to 
the American Cancer Society, one in eight women in the United States will develop breast cancer in her lifetime [7]. Although more and more effective strategies have improved patients' survival, breast cancer metastasis is still the major reason for morbidity and mortality in breast cancer patients [8-10]. Therefore, it is necessary to search for novel effective adjuvant agents to treat metastatic breast cancer.

Epithelial to mesenchymal transition (EMT) is an essential process in many human activities such as embryonic development, tissue remodeling and wound healing $[11,12]$. Studies have shown that EMT, accompanied by loss of polarity and gain of motility, plays an important role in the process of metastasis $[13,14]$. EMT is also involved in the generation of cancer stem cells (CSCs) $[13,15,16]$. CSC is a small subpopulation of cancer cells with the ability of self-renewal, contributing to cancer metastasis and chemoresistance $[17,18]$. Studies show that EMT induction and post-EMT maintenance rely on microenvironment and cytokines [19, 20]. Thus, inhibiting the inflammatory cytokine production would suppress both the EMT process and the generation of CSCs, leading to more effective therapy.

In this study, we used mouse breast cancer cell line 4T1 and human breast cancer cell line MDA-MB-231 to investigate the anti-metastasis effect of $\mathrm{SH}$ and the potential mechanisms. The in vitro experiments showed that $\mathrm{SH}$ could inhibit the migration and invasion ability of breast cancer cells. The in vivo mouse models also demonstrated that $\mathrm{SH}$ inhibited distant metastasis of breast cancer cells by reversing the EMT transition and suppressing the CSC phenotypes. SH also inhibited spleen weight and volume, as well as inflammatory factor IL-6, a very important inducing and maintenance factor in EMT and CSC, in both animal models. The inhibition effect of $\mathrm{SH}$ on EMT and CSC generation on breast cancer cells could be caused by its anti-inflammatory effect.

\section{RESULTS}

\section{SH blocked breast cancer metastasis in $4 \mathrm{T1}$ orthotopic metastatic mouse model}

4T1 cells are very aggressive murine breast cancer cells which are usually used to make models of late stage breast tumor to investigate the metastatic behavior [21]. $1 \times 10^{5} 4 \mathrm{~T} 1$ cells were injected into the left second mammary fat pad of the mice to establish an orthotopic metastatic mouse model, as the 4T1 cells were obtained from BALB/c mice, they could spontaneously metastasize to secondary foci (lymph node, lung, and liver) from the primary sites. After 4 weeks, SH treatment reduced tumor volume (Figure 1A) and tumor weight (Figure 1B). After organs were removed from the mouse under anesthesia, lung weight was measured. The results showed that the lung weight was $0.1952 \mathrm{~g}, 0.1748 \mathrm{~g}$ and $0.1672 \mathrm{~g}$ in the control, $75 \mathrm{mg} / \mathrm{kg} \mathrm{SH}$ and $150 \mathrm{mg} / \mathrm{kg} \mathrm{SH}$ groups, respectively (Figure 1F). Then the lungs were fixed and stained in Bouin's solution (Figure 1D) and lung metastatic nodules were counted (Figure 1E). The results of histological examinations of metastasis of the lungs and livers were shown in Figure 1G-1J. Compared with the control group, $150 \mathrm{mg} / \mathrm{kg} \mathrm{SH}$ treatment reduced lung index to $28.14 \%$ and liver index to $14.86 \%$. We then examined the liver function and renal function of the mice to test whether SH treatment would cause obvious toxicity on mice. The results showed that there was not statistical significance between the control group and the $\mathrm{SH}$-treated groups, indicating that $\mathrm{SH}$ treatment did not exert obvious toxicity on mice (Supplementary Table 1).

\section{SH prevented breast cancer metastasis in MDA- MB-231-luc metastatic mouse model}

To further investigate the effect of $\mathrm{SH}$ on breast cancer metastasis, MDA-MB-231-luc cells were injected into the tail vein of nude mice to establish experimental metastasis model. Mouse were injected with physiologic saline, $75 \mathrm{mg} / \mathrm{kg} \mathrm{SH}$ or $150 \mathrm{mg} / \mathrm{kg} \mathrm{SH}$. Lung metastasis was monitored by a Xenogen IVIS 2000 Imager consecutively until four weeks of the treatment (Figure 2A). SH treatment decreased the total lung fluorescence (Figure 2B). As shown in Figure 2C, more nodules could be seen on gross lung picture in the control group. From Figure 2D, we could see that $75 \mathrm{mg} / \mathrm{kg}$ and $150 \mathrm{mg} / \mathrm{kg} \mathrm{SH}$ decreased average lung weight to $0.1593 \mathrm{~g}$ and $0.1533 \mathrm{~g}$, respectively, compared with the control group of $0.1774 \mathrm{~g}(p=0.147$ and $p=0.048$, respectively). Although there was a decrease trend of lung weight in low dose $\mathrm{SH}$ treatment, there was no statistical significance. It could be due to the relative small number of the samples. The microscopic lung metastasis was evaluated using the same method as in the 4T1 orthotopic metastasis model. After treatment with physiologic saline, $75 \mathrm{mg} / \mathrm{kg}$ and 150 $\mathrm{mg} / \mathrm{kg} \mathrm{SH}$, the lung index was $51.17 \pm 7.25,28.50 \pm 9.88$ and $20.00 \pm 6.95$, respectively. Compared with the control group, $75 \mathrm{mg} / \mathrm{kg} \mathrm{SH}$ treatment reduced lung index to $55.70 \%$ and $150 \mathrm{mg} / \mathrm{kg} \mathrm{SH}$ reduced lung index to $39.09 \%$. Supplementary Figure 2 showed a very small increase in weight in all groups without significant difference between the control group and the treated groups. Supplementary Table 2 demonstrated no significant liver and renal function changes of $\mathrm{SH}$ in comparison with physiologic saline. Supplementary Figure 2, together with Supplementary Table 2 suggested the relative safety of SH at the chosen doses.

\section{SH decreased MMP-9 and increased TIMP-1 and TIMP-2 expression}

Cancer metastasis is a complex process including tumor cell adhesion to extracellular matrix (ECM), 
migration, invasion and other intravascular and extravascular activates [22]. During the invasion and metastasis process, cancer cells need to increase matrix metalloproteinase (MMP) expression and decrease tissue inhibitor of metalloproteases (TIMP) expression to degrade ECM $[23,24]$. We first detected the serum levels of MMP-2, MMP-9, TIMP-1 and TIMP-2 in both mouse models by enzyme-linked immunosorbent assay (ELISA). For the 4T1 mouse model, the results showed that SH treatment decreased MMP-9 serum level, while
A

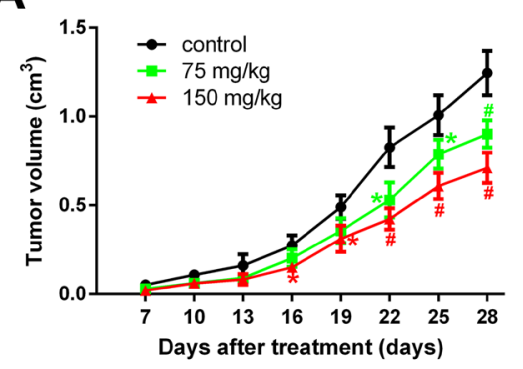

D
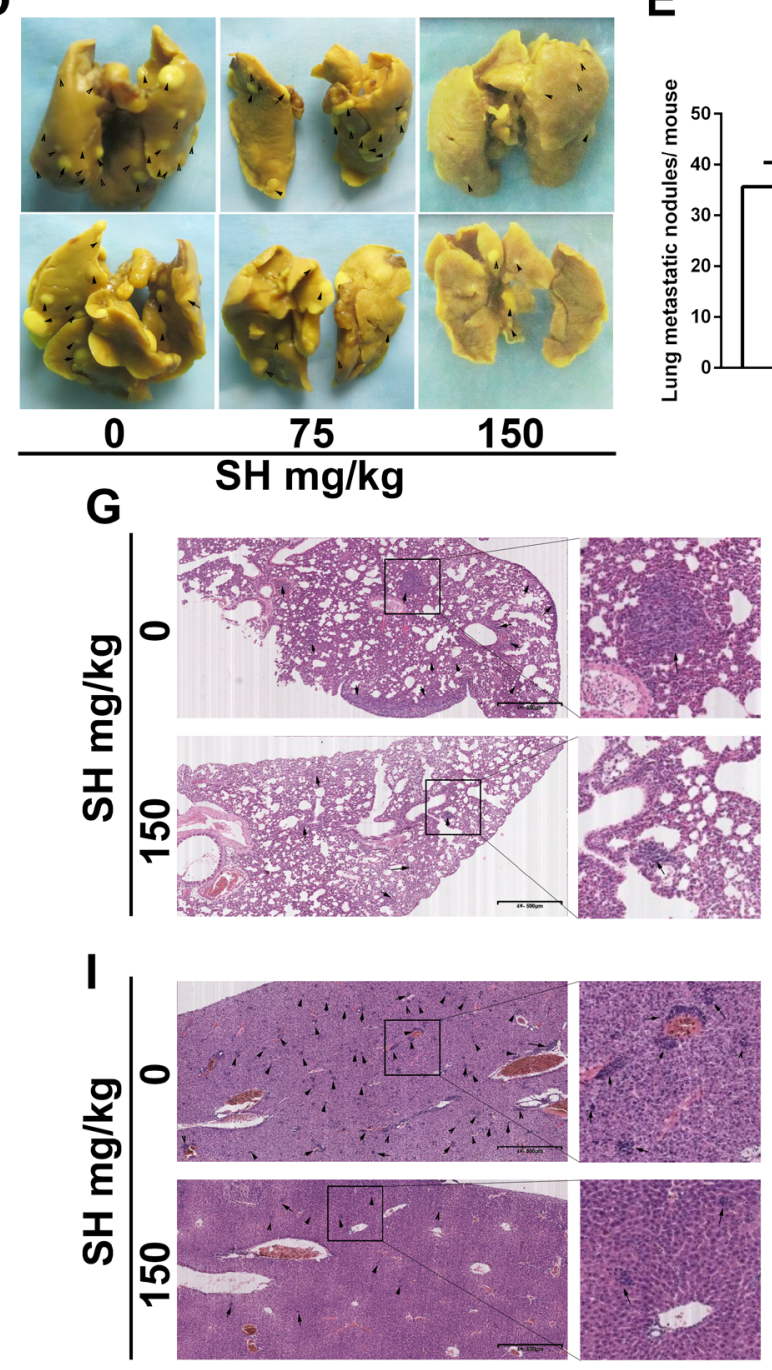

B

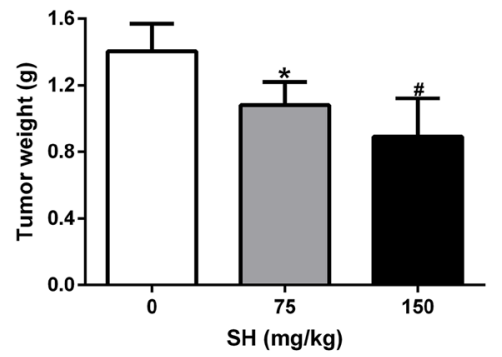

E

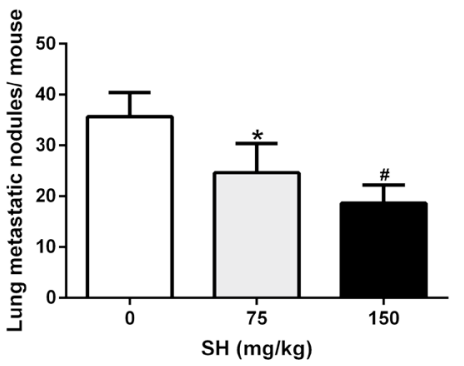

H
C

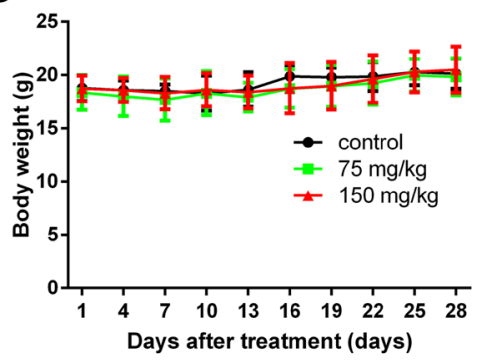

F

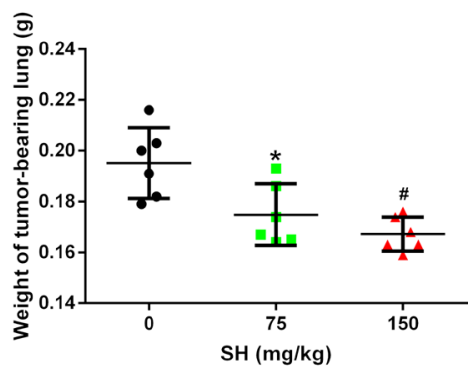

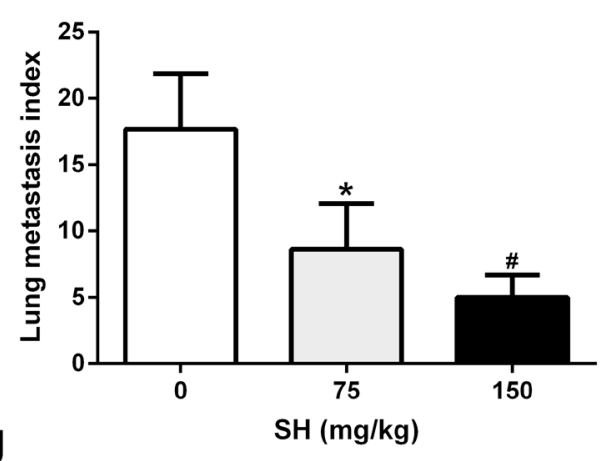

J

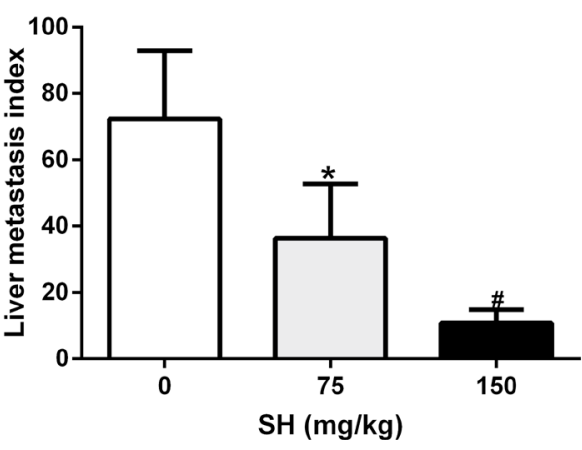

Figure 1: SH inhibited breast cancer metastasis in a 4T1 metastatic mouse model. BALB/c mice bearing 4T1 mouse breast homograft were treated with physiologic saline or different doses of SH. (A) Time course of primary tumor volume. (B) Primary tumor weight. (C) Body weight. (D) Representative lung pictures fixed by Bouin's solution. Metastatic foci on the gross tissue were marked with black arrows. (E) Lung metastatic nodules per mouse. (F) Lung weight. (G) HE staining of lung specimen and (H) lung metastasis index. (I) HE staining of liver specimen and (J) liver metastasis index. Data are represented as mean \pm S.D. of three independent experiments. ${ }^{*} P<0.05,{ }^{\#} P<0.01$, SH treated group compared with the untreated control group. 
A

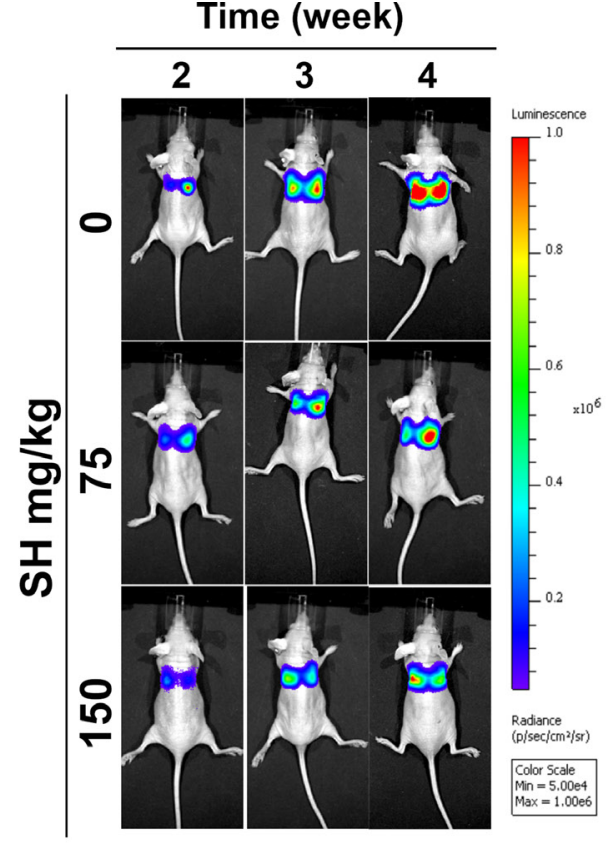

B

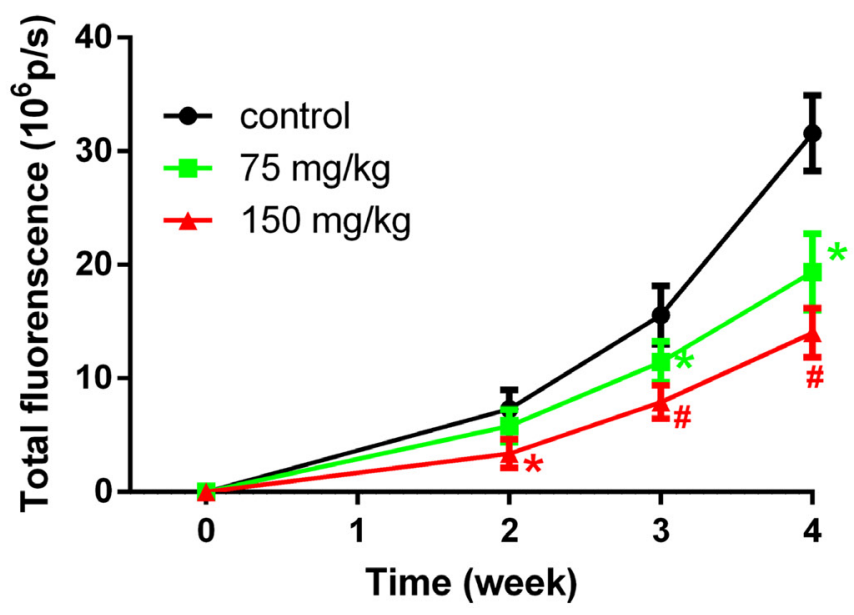

D

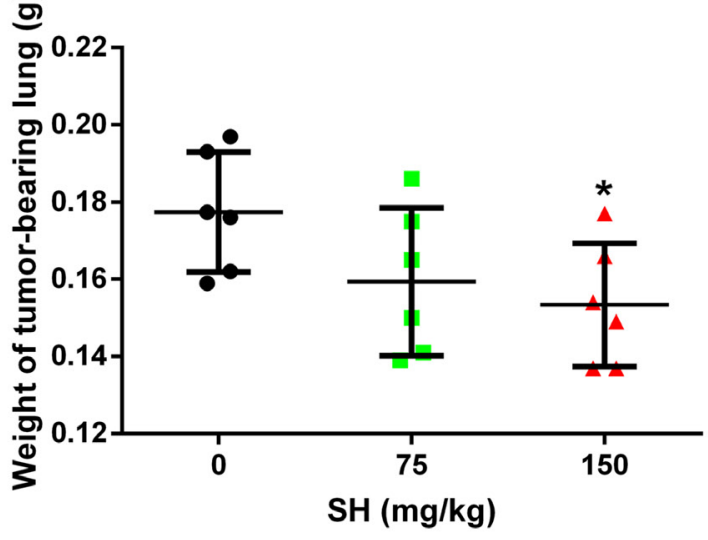

F

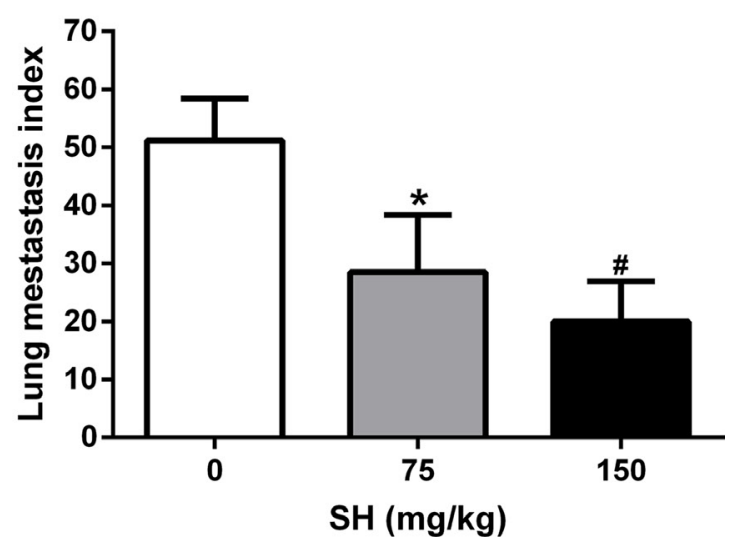

Figure 2: SH reduced pulmonary metastasis in an MDA-MB-231-luc experimental metastatic mouse model. BALB/c mice were injected with MDA-MB-231-luc via tail vein. (A) Representative bioluminescence images of lung metastasis. Luciferin was injected i.p. and lung metastasis was monitored by a Xenogen IVIS 2000 Imager at the indicated time points. The color scale to the right of the image showed the intensity range of photon flux per second. (B) The quantification of total lung fluorescence. (C) Representative pictures of gross lung. Black arrows indicated metastatic nodules. (D) Lung weight. (E) HE staining of lung specimen and (F) lung metastasis index. Data are represented as mean \pm S.D. of three independent experiments. ${ }^{*} P<0.05,{ }^{\#} P<0.01$, SH treated group compared with the untreated control group. 
increased TIMP-1 and TIMP-2 serum levels (Figure 3B-3D). However, no significant change of MMP-2 was detected (Figure 3A). For the MDA-MB-231 mouse model, as we detected human breast cancer cell excretion in mouse serum, the level of these markers were very low. Therefore, it required large quantity of serum far beyond the serum volume of the samples, and due to the very low concentrations of these tested markers, the established ELISA standard curve in our preliminary experiments showed that it was not accurate enough to predict the samples at such low concentrations.

We further used IHC to reaffirm the results of MMP9, TIMP-1 and TIMP-2. In 4T1 tumor section specimens, we found that $150 \mathrm{mg} / \mathrm{kg}$ decreased MMP-9 to $38.54 \%$ compared with $75 \%$ in the control group, increased TIMP-1 to $76.04 \%$ compared with $31.25 \%$ in the control group, and increased TIMP-2 to $66.15 \%$ compared with $33.33 \%$ in the control group, respectively. We also could detect changes in MMP-9, TIMP-1 and TIMP-2 in the lung section specimens of MDA-MB-231 experimental mouse model. SH treatment decreased MMP-9 to $30.21 \%$ compared with $52.08 \%$ in the control group, increased TIMP-1 to $75 \%$ compared with $32.29 \%$ in the control group, and increased TIMP-2 to $57.29 \%$ compared with $35.42 \%$ in the control group, respectively. The change of TIMP/MMP meant that SH could inhibit breast cancer cells from degrading ECM, thus preventing metastasis.

\section{SH impaired migration and invasion ability and inhibited EMT process in breast cancer cells}

Since EMT is recognized for its role in tumor metastasis $[11,15]$, we then examined whether SH could reverse the EMT process in breast cancer cells. As EMT process often facilitates cancer cell motility and invasion, we examined the effect of $\mathrm{SH}$ on cancer cell migration in vitro. Wound healing assay was first used to measure the effect of SH on cancer cell migration. As shown in Figure 4A, after treatment with SH, a clear time- and dose-dependent inhibition was observed. After treatment with 0.25 and $0.5 \mu \mathrm{mol} / \mathrm{mL} \mathrm{SH}$ for $24 \mathrm{~h}$, the migration areas were about $68.52 \%$ and $62.88 \%$ of that of the control group for $4 \mathrm{~T} 1$, respectively, and $88.79 \%$ and $63.68 \%$ of that of the control group for MDA-MB-231, respectively.

Transwell migration method was used to confirm the impairment of SH on the migration ability of 4T1 and MDA-MB-231. Treatment with SH at 0.25 and $0.5 \mu \mathrm{mol} /$ $\mathrm{mL}$ significantly impaired the migration ability of $4 \mathrm{~T} 1$ and MDA-MB-231. The inhibition rates of $0.5 \mu \mathrm{mol} / \mathrm{mL}$ SH for $4 \mathrm{~T} 1$ and MDA-MB-231 were $59.94 \%$ and $72.9 \%$, respectively (Figure 4B) Similar results were found in the matrigel-coated transwell invasion assay. The results showed that $0.5 \mu \mathrm{mol} / \mathrm{mL} \mathrm{SH}$ inhibited the invasion ability of $4 \mathrm{~T} 1$ and MDA-MB-231 to $60.77 \%$ and $65.28 \%$ of that of the control group, respectively (Figure 4C).
We then detected some EMT markers in 4T1 and MDA-MB-231 cell lines in vitro. After treatment of SH for $24 \mathrm{~h}$, the western blot results (Figure 5A) showed that $\mathrm{SH}$ treatment increased the epithelial marker E-cadherin, and decreased the mesenchymal marker $\mathrm{N}$-cadherin and vimentin in $4 \mathrm{~T} 1$ cell line. However, the downregulation of N-cadherin was not obvious in MDA-MB-231 cell line which could be due to different response of different cell lines at the same time.

We also detected some markers using samples from mouse models. Figure 5B showed that $\mathrm{SH}$ treatment increased E-cadherin from $26.04 \%$ in the control group to $48.96 \%$ in the $150 \mathrm{mg} / \mathrm{kg}$ group of the tumor specimens and from $2.08 \%$ to $19.79 \%$ of the lung samples. In contrast, SH treatment decreased N-cadherin from $67.13 \%$ in the control group to $30.73 \%$ in the $150 \mathrm{mg} / \mathrm{kg}$ group of the tumor specimens and from $59.90 \%$ to $32.29 \%$ of the lung samples (Figure 5C). These results suggested the reverse of EMT by SH treatment.

\section{SH suppressed CSC characteristics in breast cancer cells}

EMT and CSC are interrelated with each other. Evidence have shown that EMT could induce CSC characteristics [16]. We wondered whether inhibition of EMT by SH could contribute to some changes in the CSC characteristics. Mammosphere formation is good a way to assess self-renewal ability of CSCs, involving in vitro spheroids formation in the non-adherent culture conditions. The results showed that $\mathrm{SH}$ decreased the number of sphenoid colonies of both 4T1 and MDAMB-231 (Figure 6A). The number of sphenoid colonies of 0 and $0.5 \mu \mathrm{mol} / \mathrm{mL} \mathrm{SH}$ treatment was 74.33 and 46.67 for 4T1, respectively $(p<0.01)$. The number of sphenoid colonies of 0 and $0.5 \mu \mathrm{mol} / \mathrm{mL} \mathrm{SH}$ treatment was 40.67 and 26.33 for MDA-MB-231, respectively $(p<0.05)$.

CD44 and Sox-2 are both markers of stem cancer cell. We used flow cytometer to assess CD44 changes in MDA-MB-231 and 4T1 cell lines first. Figure 6B showed $0.5 \mu \mathrm{mol} / \mathrm{mL}$ SH decreased expression of CD44 on cell membrane in both cell lines. We then evaluated their expression in tumor samples and lung samples. Figure 6C-6D demonstrated that SH decreased CD44 and Sox-2 in both mouse models, suggesting the inhibition of CSC by $\mathrm{SH}$ treatment.

\section{SH inhibited inflammation response elicited by breast cancer cells}

$\mathrm{SH}$ is famous for its remarkable anti-inflammation effect in rheumatic arthritis. Most of the previous studies also focused more on its anti-inflammatory effect. EMT is also known for its induction and maintenance by cytokines and inflammatory factors $[19,20]$. We wondered whether the inhibition of EMT and CSC was due to the anti- 
inflammation of SH. Obvious decreases of spleen volume and weight were found in the 4T1 orthotopic mouse model (Figure 7A and 7B). The results showed that the volume of the control group was $2.58 \mathrm{~cm}^{3}$, the $75 \mathrm{mg} / \mathrm{kg}$ group was $1.45 \mathrm{~cm}^{3}$, and the $150 \mathrm{mg} / \mathrm{kg}$ group was $1.24 \mathrm{~cm}^{3}$. The spleen weight of the control group, the $75 \mathrm{mg} / \mathrm{kg}$ and the $150 \mathrm{mg} / \mathrm{kg}$ group were $0.6885 \mathrm{~g}, 0.3993 \mathrm{~g}$ and $0.3593 \mathrm{~g}$, respectively. There is significant difference of between the control group and the treatment groups. For the MDA-MB231-luc mouse model, SH treatment also decreased both the spleen volume and spleen weight (Figure 7C and 7D). However, despite of a decrease trend in spleen volume, there was no significance between the control group and the treatment groups ( $p=0.278$ for control vs $75 \mathrm{mg} / \mathrm{kg}$ group; $p=0.052$ for control vs $150 \mathrm{mg} / \mathrm{kg}$ group).

IL-6 is one of the famous factors inducing EMT and also has been shown to be reduced by $\mathrm{SH}$. We then detected the expression of IL-6 inflammatory factors in tumor specimens of 4T1 and lung specimens of MDAMB-231. Figure $7 \mathrm{~F}$ and $7 \mathrm{G}$ showed that $150 \mathrm{mg} / \mathrm{kg} \mathrm{SH}$ decreased IL-6 to $89.58 \%$ compared $56.25 \%$ with the control group in 4T1 tumor specimens. Similar results were found in the MDA-MB-231 lung specimens. IL-6 could be secreted by many inflammatory cells as well as tumor cells. We wondered whether the reduction of IL-6 in mouse samples was a direct effect on tumor cells or was an indirect effect on inflammatory cells. We then detected the effect of SH on IL-6 expression in vitro to help us answer this question. IL-6 is mainly secreted by monocytes, macrophages, neutrophils and some types of T cells in body [25]. RAW 246.7 is a murine macrophage cell line that could be cultured in vitro. We selected RAW 246.7 as the representative inflammatory cell line as macrophage is one of the main production of IL-6 in

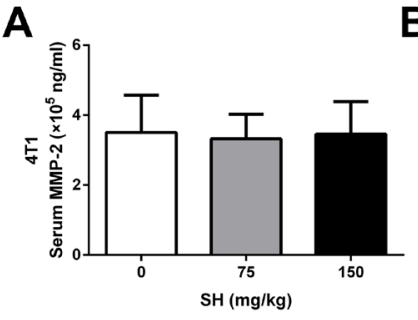

E

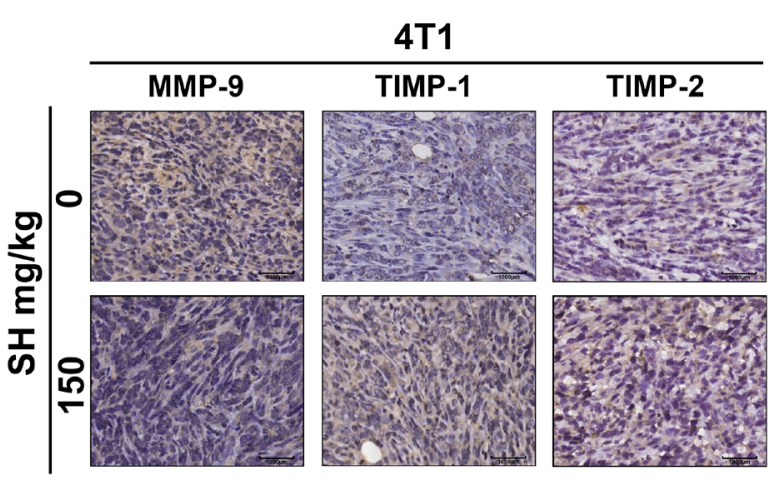

G

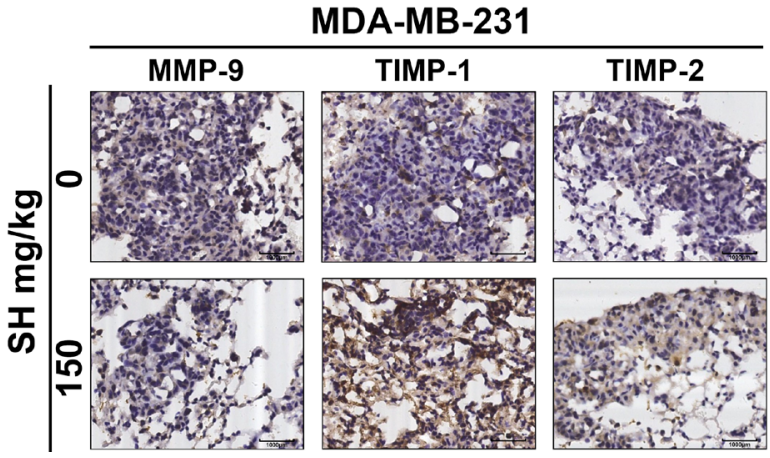

B

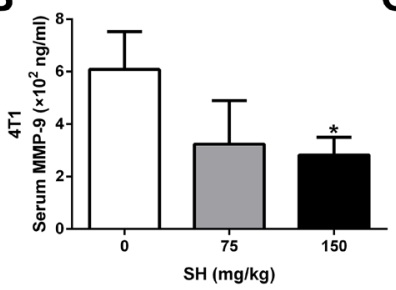

4T1
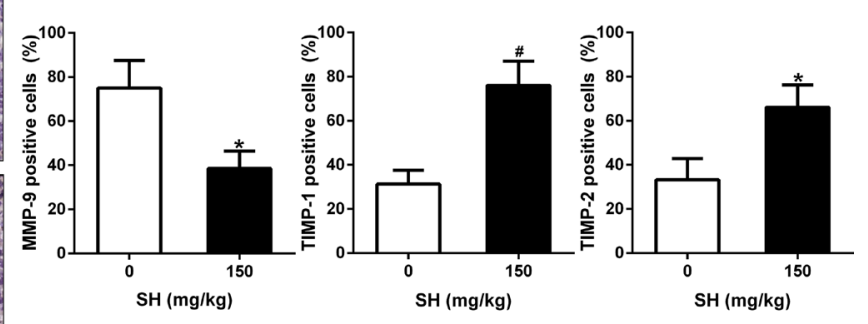

H

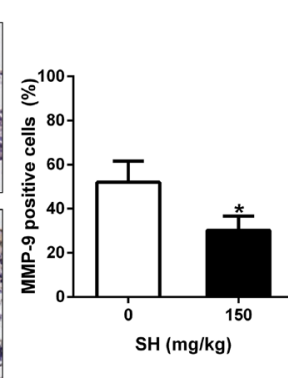

D

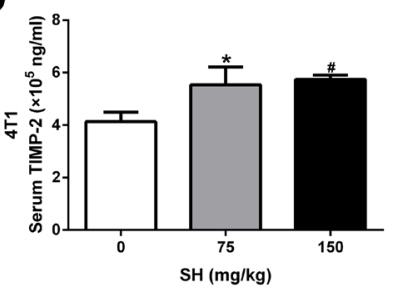

F

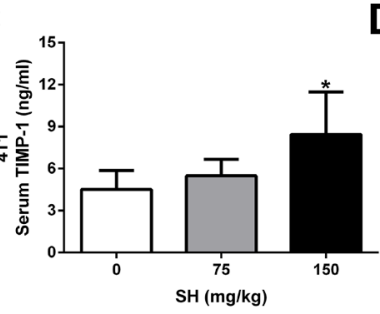

F

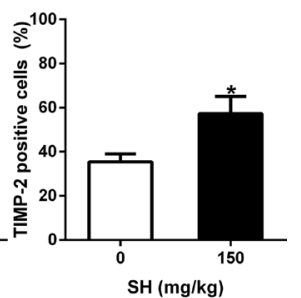

Figure 3: SH decreased MMP-9 and increased TIMP-1, TIMP-2 levels in both mouse model. Serum samples and section specimen were used to detect these markers. In the 4T1 mouse model, (A) MMP-2, (B) MMP-9, (C) TIMP-1 and (D) TIMP-2 serum levels were tested using ELISA. (E) IHC staining and (F) quantification of MMP-9, TIMP-1 and TIMP-2 expression in 4T1 tumor specimens. (G) IHC staining and (H) quantification of MMP-9, TIMP-1 and TIMP-2 expression in MDA-MB-231 lung specimens. Data are represented as mean \pm S.D. of three independent experiments. ${ }^{*} P<0.05,{ }^{\#} P<0.01$, SH treated group compared with the untreated control group. 
A
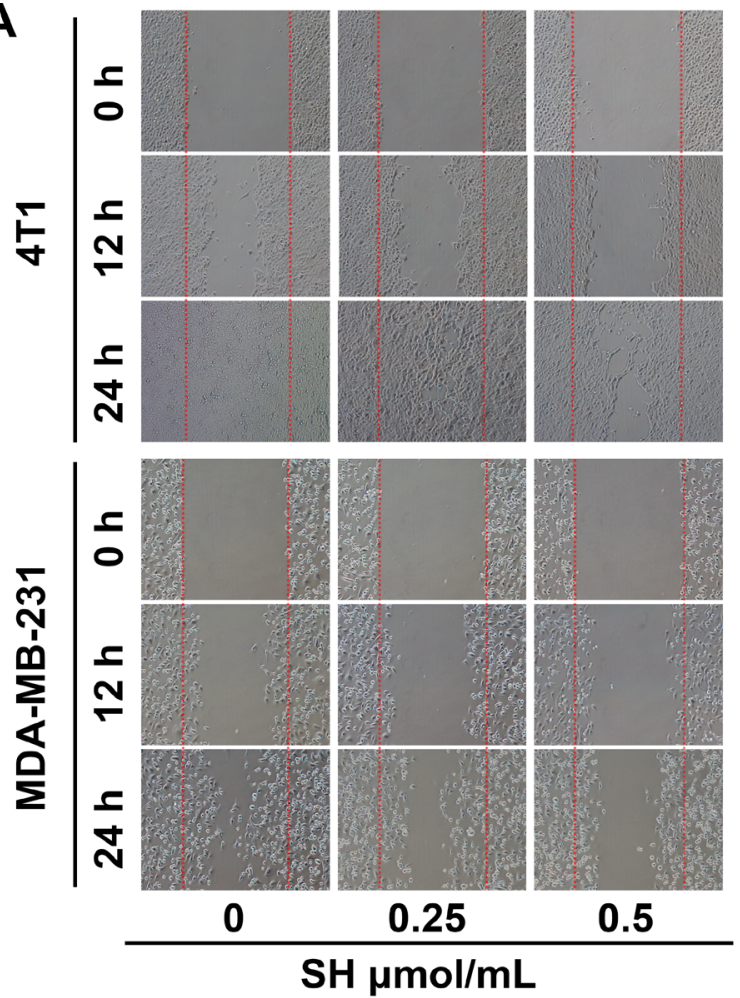

B

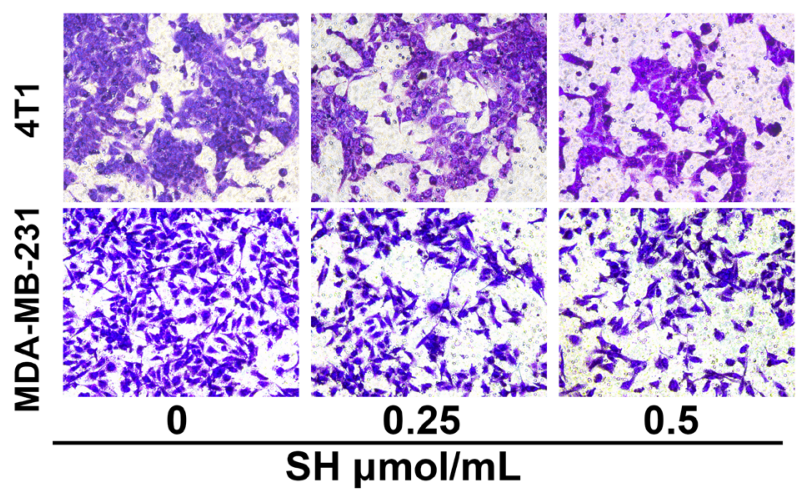

C

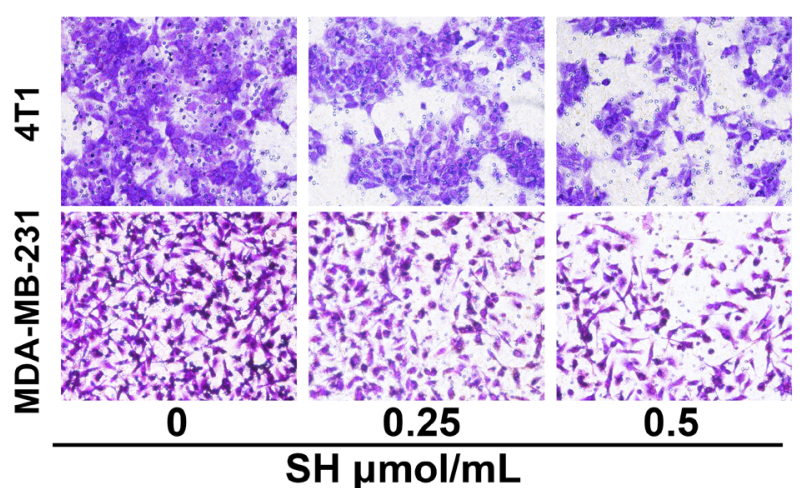

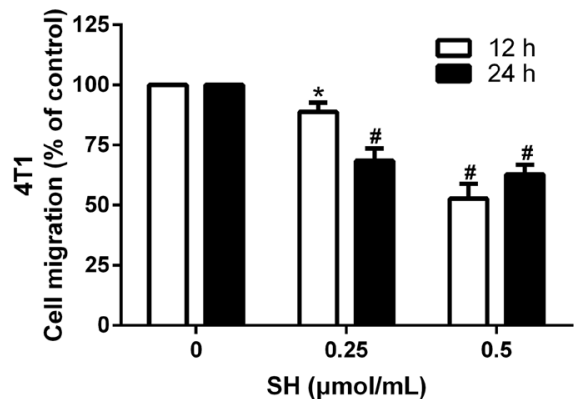
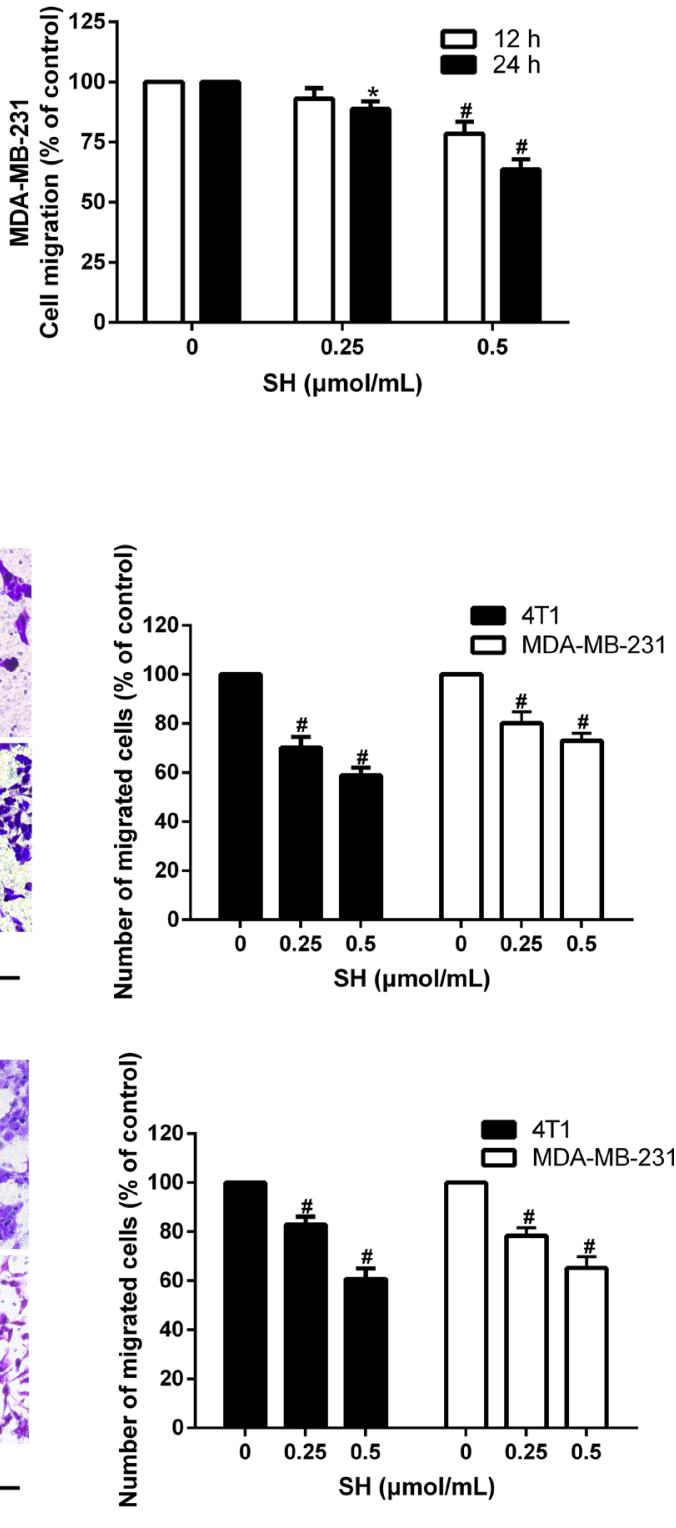

Figure 4: SH impaired the migration and invasion ability of 4T1 and MDA-MB-231 cells. (A) Confluent cells were scratched and treated with SH for 12 and $24 \mathrm{~h}$. Cells migrating into the scratched area were photographed $(\times 40)$. Cell migration ability was assessed by migration area. (B) 4T1 and MDA-MB-231 cells were cultured with different doses of SH in the upper transwell chambers. After migrating for $24 \mathrm{~h}$, cells on the bottom of the filter were fixed, stained and photographed $(\times 200)$. The migrated cells were dissolved in $30 \%$ acetic acid and measured by a microplate reader at $570 \mathrm{~nm}$. (C) SH inhibited the invasion ability of $4 \mathrm{~T} 1$ and MDA-MB-231 cells. Matrigel was coated on the transwell chambers. After $24 \mathrm{~h}$, the invaded cells were photographed $(\times 200)$ and quantified by a microplate reader at 570 $\mathrm{nm}$. All data are represented as mean \pm S.D. of three independent experiments. ${ }^{*} P<0.05,{ }^{\#} P<0.01$, SH treated group compared with the untreated control group. 
human. We found that SH decreased IL-6 secretion in both MDA-MB-231 and RAW 246.7 cells. For 4T1 cell line, however, the concentration of IL-6 was too low to fall into the proper range of the ELISA kit.

\section{DISCUSSION}

Although many preventive methods and diagnostic methods have been made to try to detect breast cancer in early stages, there are still a lot of people diagnosed at late stages or with metastasis. Besides, some patients are found initially sensitive to chemotherapy, but later develop chemoresistance and metastasis. As we know most breast cancer mortality results from cancer relapse with invasion and metastasis [6, 26, 27], therefore, effective decrease or treatment of metastasis is important to improve life quality and increase life survival for breast cancer patients.

Cancer metastasis is a complex biological event including two main parts, namely the intravasation process, in which cancer cells of local tumors invade the basement membrane and circulate through the blood, and the extravasation process, in which the cancer cells escape

A
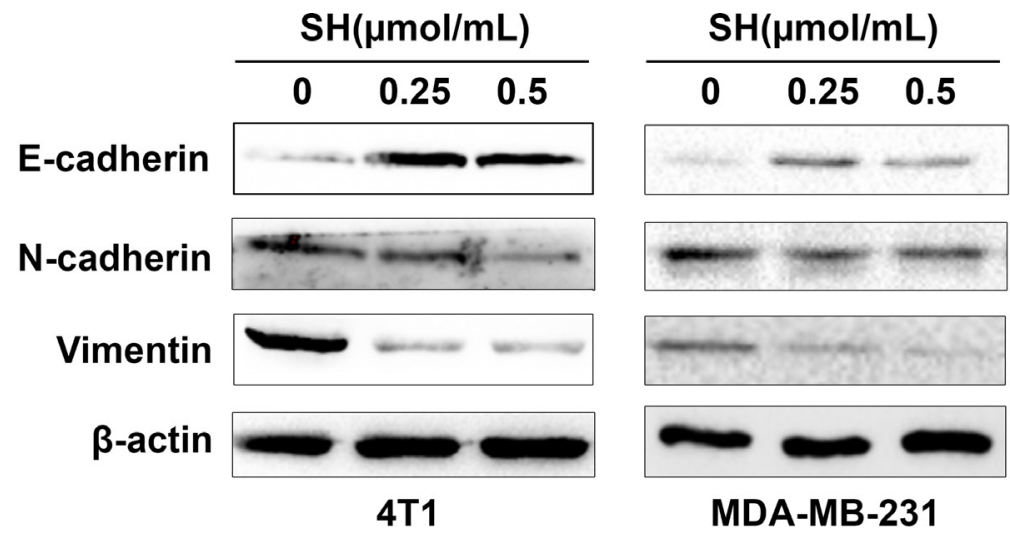

B
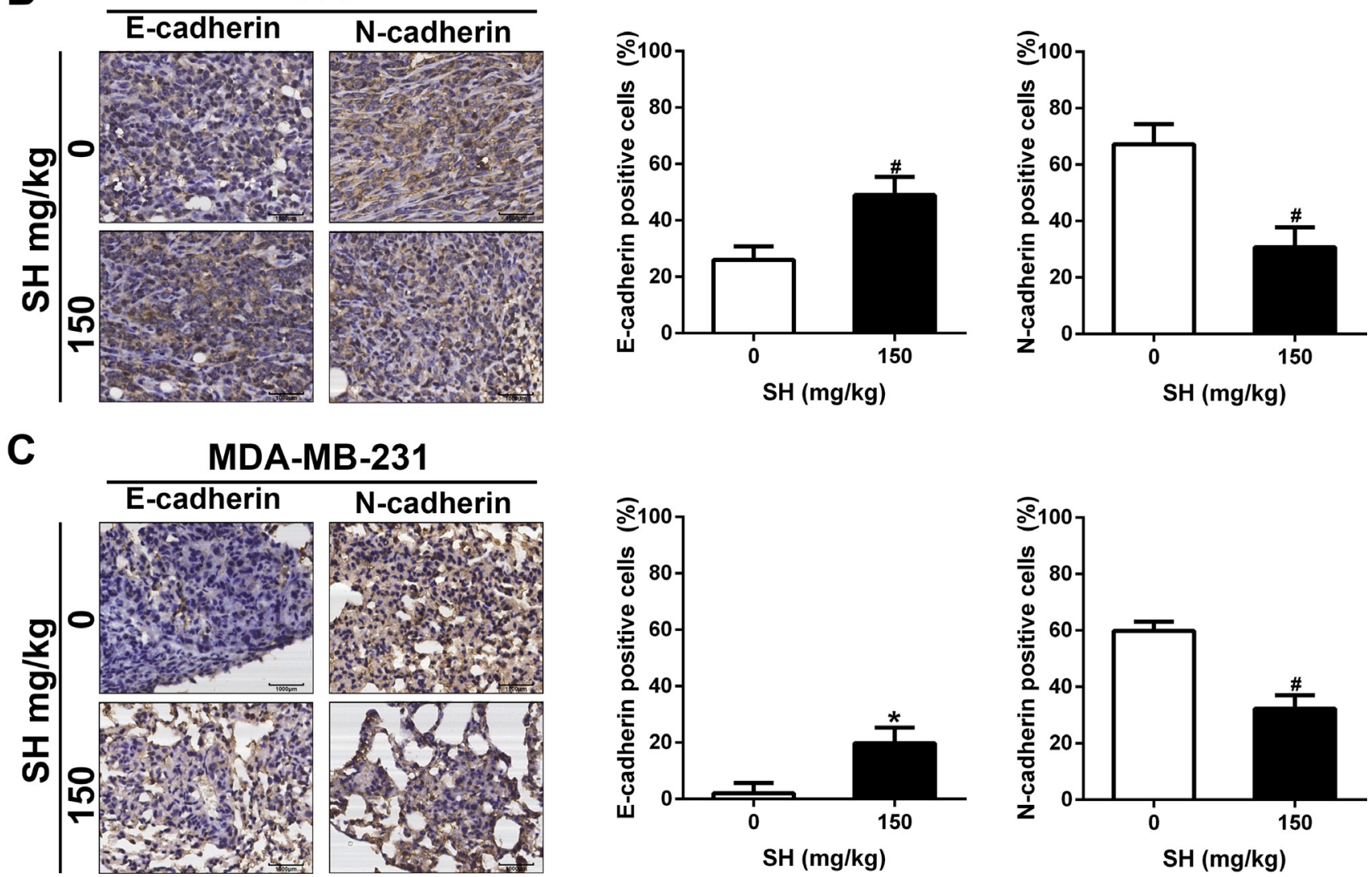

Figure 5: SH reversed EMT process in breast cancer cells. (A) Proteins involved in EMT process were analyzed by western blot. (B and $\mathbf{C}$ ) IHC analysis of EMT markers E-cadherin and N-cadherin in tumor specimens of 4T1 and lung specimens of MDA-MB-231. 
A

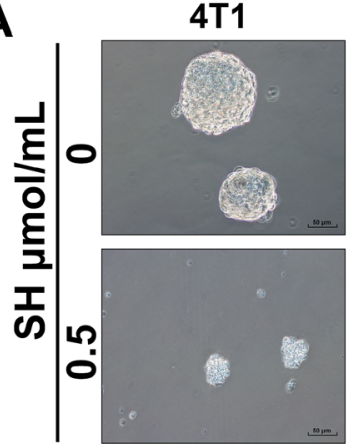

B
MDA-MB-231

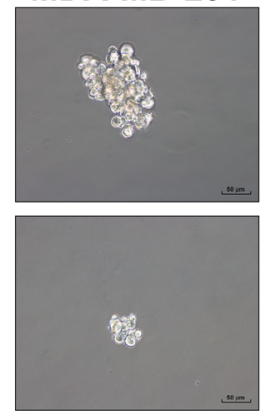

MDA-MB-231
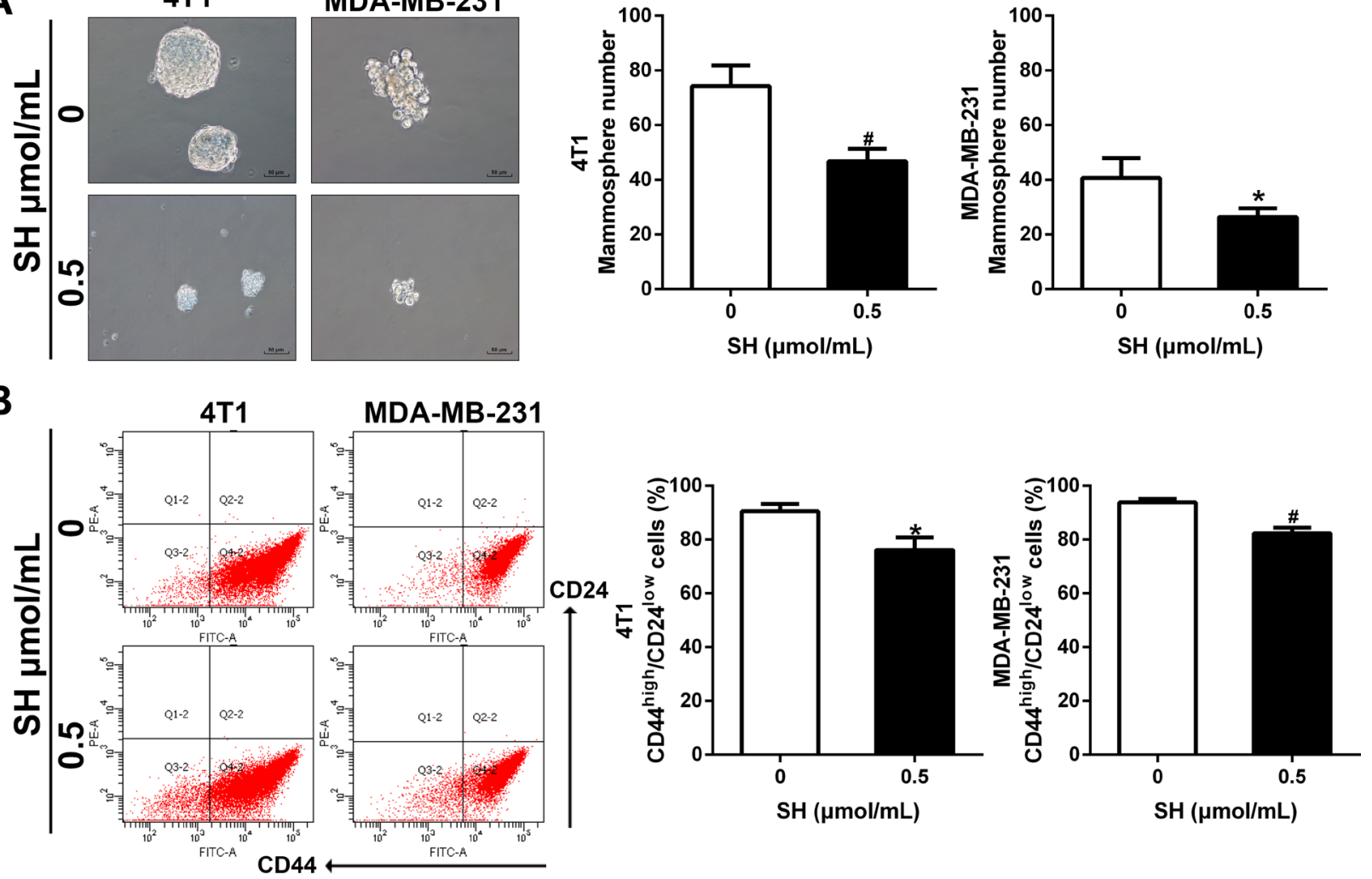

C

4T1
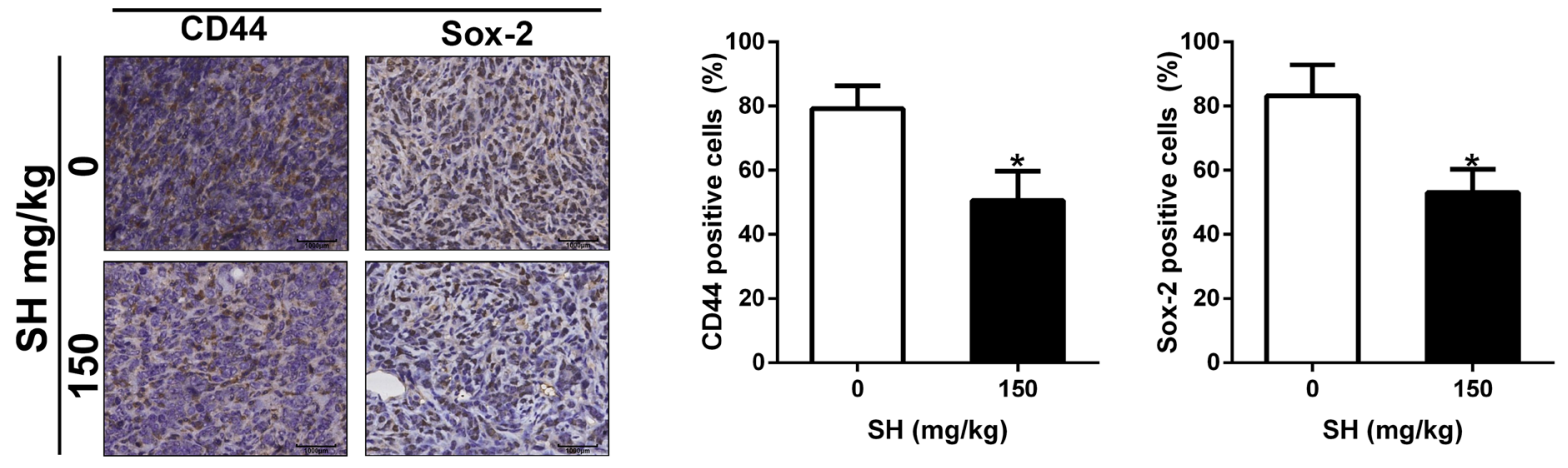

D
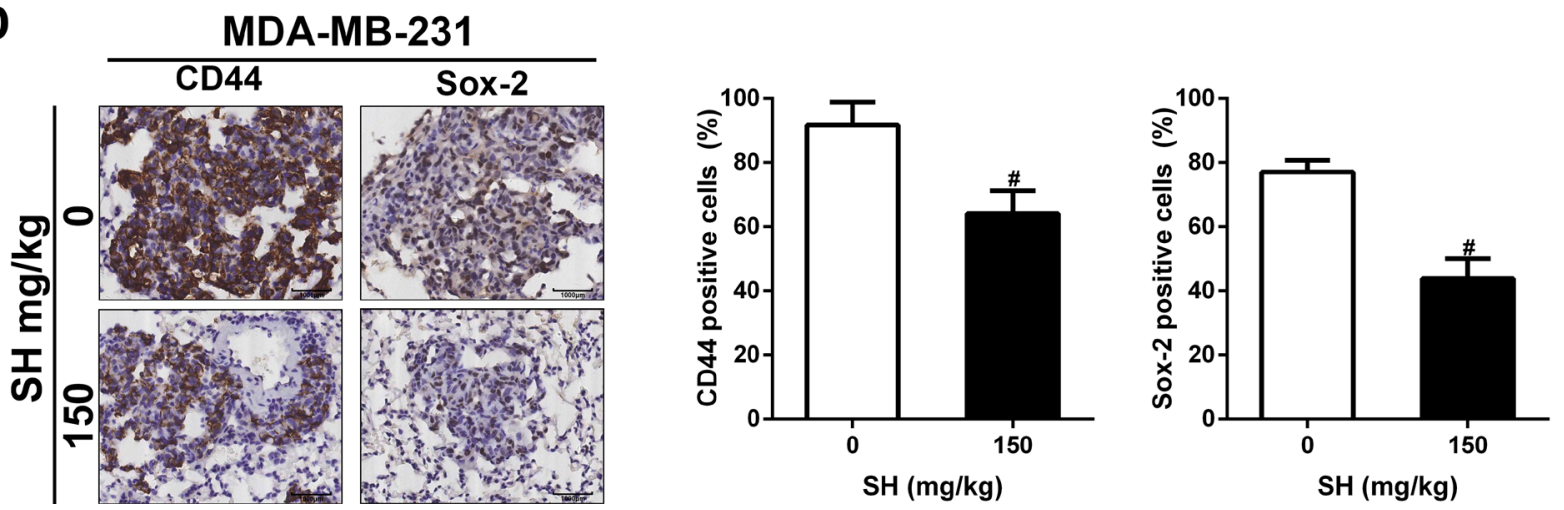

Figure 6: SH inhibited CSC characteristics in breast cancer cells. (A) Mammosphere formation and its quantification. 4T1 and MDA-MB-231 were treated with SH for $48 \mathrm{~h}$, harvested and seeded on ultra-low attachment culture plates. Mammospheres with diameter $>50 \mu \mathrm{m}$ were counted on day 10. (B) CSC markers CD44 and Sox-2 were analyzed by western blot. (C and D) IHC analysis of CD44 and Sox-2 in tumor specimens of 4T1 and lung specimens of MDA-MB-231. Data are represented as mean \pm S.D. of three independent experiments. ${ }^{*} P<0.05,{ }^{\#} P<0.01$, SH treated group compared with the untreated control group. 
from the capillary wall and survive at distant organ sites [28] . Our previous studies found that SH could effectively inhibited breast cancer cell proliferation [5]. In this study, we investigated the anti-metastasis effect of $\mathrm{SH}$ on breast cancer cells in both mouse models of breast cancer.

Choosing suitable models which could mimic the real metastatic process is the first step to study breast cancer metastasis. In the orthotopic metastatic mouse model, cancer cells need to go through both the intravasation and extravasation processes to initiate tumor formation on a new site. 4T1 murine mammary carcinoma cells were always used for its highly metastatic potential in immunocompetent mice. 4T1 mouse model, a model of late-stage breast cancer [29, 30], was chosen to assess the effect of $\mathrm{SH}$ on the whole metastatic process from the primary tumor location to the new site via the hematogenous pathway. We found significant differences between the control group and the SH-treated groups.
$75 \mathrm{mg} / \mathrm{kg}$ and $150 \mathrm{mg} / \mathrm{kg} \mathrm{SH}$ both decreased the tumor volume and tumor weight in comparison with the control group. More important, SH treatment inhibited lung weight, indicating the anti-metastatic ability of SH. From a microscopic view, $\mathrm{SH}$ reduced both lung and liver metastatic index, demonstrating that SH could inhibit new metastatic foci of breast cancer tumors.

Although 4T1 orthotopic mouse model represents the natural metastatic event more authentically, it has a disadvantage, namely $4 \mathrm{~T} 1$ is a murine cell line. Thus we still wanted to examine the anti-metastatic effect of $\mathrm{SH}$ on human breast cancers. Meanwhile, SH treatment inhibited primary tumor growth which could influence tumor cell metastasis [31]. In the experimental metastatic mouse model, MDA-MB-231-luc human breast cancer cells were introduced directly into the tail vein and passed through the lung microvasculature [22]. This model mainly mimics the extravasation process of metastasis. The cell line was
A

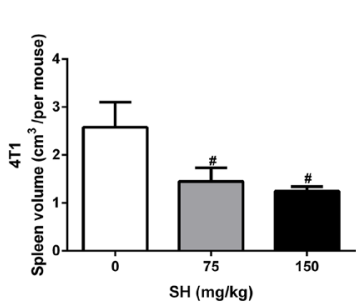

B

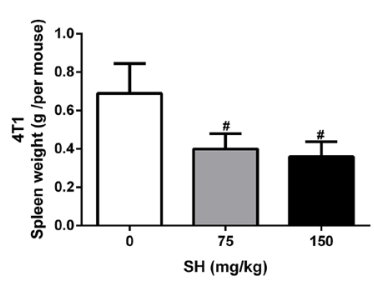

C

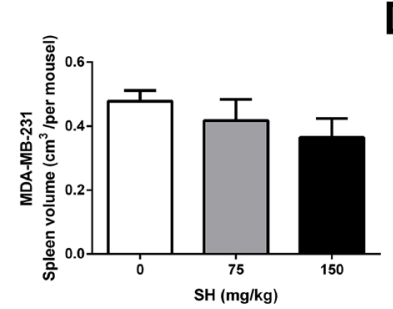

D

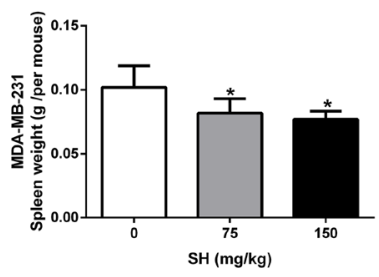

E

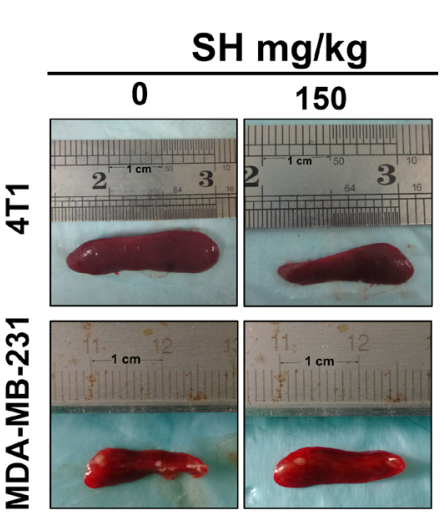

F $\quad \mathrm{SH} \mathrm{mg} / \mathrm{kg}$

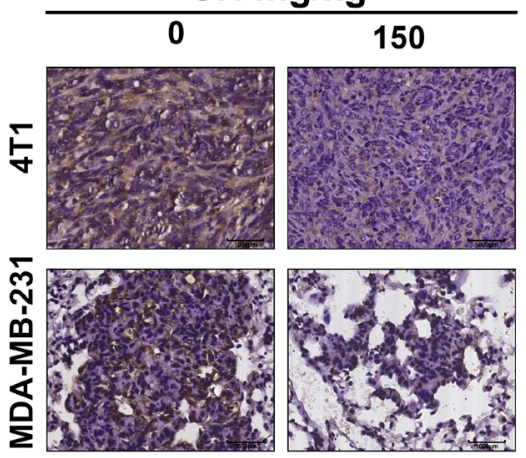

G
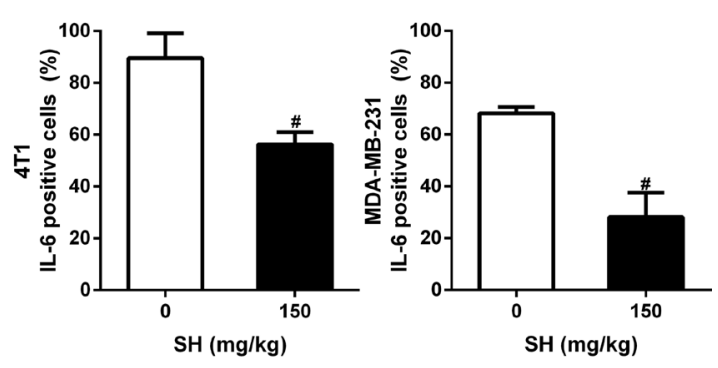

H
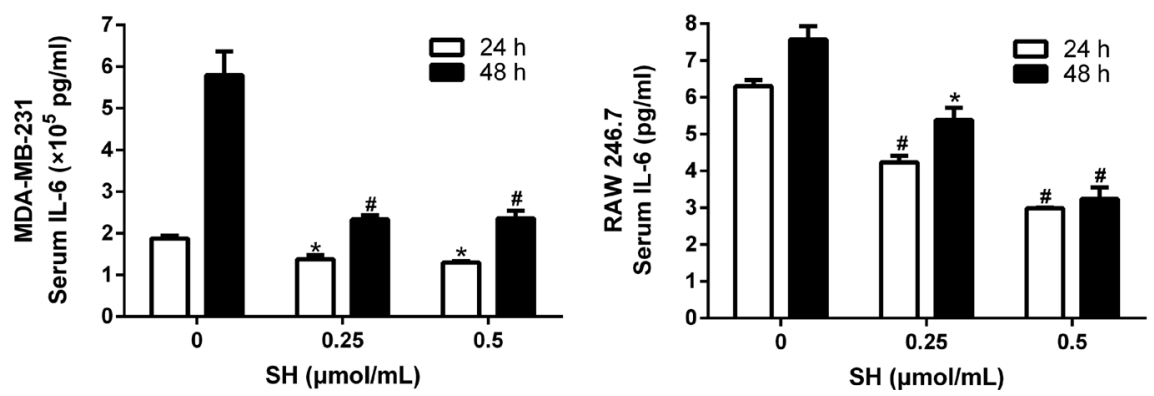

Figure 7: SH attenuated inflammation response elicited by breast cancer cells. (A) Spleen volumes and (B) spleen weight of the control group, $75 \mathrm{mg} / \mathrm{kg}$ and $150 \mathrm{mg} / \mathrm{kg}$ SH groups in the 4T1 mouse model. (C) Spleen volumes and (D) spleen weight of the control group, $75 \mathrm{mg} / \mathrm{kg}$ and $150 \mathrm{mg} / \mathrm{kg} \mathrm{SH}$ groups in the MDA-MB-231-luc mouse model. (E) Representative spleen pictures. (F and G) IL-6 expression analysis by IHC. (H) IL-6 secretion of cells was tested using ELISA. MDA-MB-231 cancer cells and RAW 246.7 murine macrophages were treated with SH and the supernatant was used to test IL-6 secretion. Data are represented as mean \pm S.D. of three independent experiments. ${ }^{*} P<0.05,{ }^{\sharp} P<0.01$, SH treated group compared with the untreated control group. 
modified with firefly luciferase, allowing us to monitor the lung metastasis non-invasively and dynamically [30]. We found that SH treatment decreased the lung metastasis during the consecutive monitor. Overall, both animal models suggested the strong anti-invasion and metastatic effects of $\mathrm{SH}$.

In order to metastasize to new sites, cancer cells need to degrade down the ECM. MMPs and TIMPs act together to control ECM degradation $[32,33]$. Therefore, MMPs and TIMPs changes are good markers of the metastatic activity of cancer cells. Research have shown that both MMPs and TIMPs are involved in breast cancer progression [24, 34]. Some studies even showed the different breast cancer subtypes contained different MMPs and TIMPs patterns $[35,36]$. Here, we found that $\mathrm{SH}$ could inhibit MMP-9 and increased TIMP-1 and TIMP2 both serum levels and cell expression levels in 4T1 mouse model. However, we only detected the same cell expression changes in MDA-MB-231-luc mouse model due to very low concentrations of these factors in serum. The decreased MMP-9 and increased TIMP-1 and TIMP-2 together indicated a change of metastatic activity after $\mathrm{SH}$ treatment in the two mouse models.

EMT is demonstrated to play a role in the development of invasion, metastasis and therapy resistance [15]. EMT is an essential process during embryo genesis and adult tissue repair and maintenance, with characteristics of loss of epithelial traits such as cell-cell adhesion and acquisition of mesenchymal properties such as acquisition of motility $[15,37]$. It is accompanied by decrease epithelial markers such as E-cadherin, occludins and claudins, and increase mesenchymal markers such as $\mathrm{N}$-cadherin and vimentin. E-cadherin is expressed at cellcell adhesion junctions and required for the formation of epithelia during the embryo period and maintenance of epithelia homeostasis in adulthood [37]. Research have shown that low E-cadherin is related to higher tumor grade and stage, meanwhile, loss or genetic mutation of E-cadherin expression contributes cancer development [38]. However, E-cadherin reduction alone is not sufficient enough for EMT $[38,39]$. The EMT also includes the acquisition of mesenchymal properties. We then started the investigation of EMT by examine the expression changes of the markers. Here, we reported that $\mathrm{SH}$ treatment increased E-cadherin while decreased $\mathrm{N}$-cadherin in tumor specimens of 4T1 mouse model and lung specimens of MDA-MB-231-luc mouse model, suggesting $\mathrm{SH}$ could inhibit EMT, which might contribute its anti-invasion and anti-metastatic potentials.

Research have shown that cells that undergo EMT also acquire stem cell-like properties [16]. CSCs were discovered first in the hematopoietic system and later in human solid tumors such as breast cancer and brain cancer [40-42]. CSCs are a small population of neoplastic cells within a tumor with self-renewal capability and tumor initiating ability and are shown to play a role in the malignant process of tumors, such as drug resistance, invasion and metastasis [15]. EMT enables cancer cells the ability to metastasize as well as the ability to replicate in order to form new tumor foci $[13,16]$. The pluripotent cell marker includes but not limits to CD44, OCT4, SOX2, Klf4 and Nanog. CD44, a cell-surface glycoprotein involved in cell adhesion and migration, is recognized as one of the important CSC markers, especially in mammary CSCs [43]. There are also some studies showing that Sox2 , but not OCT4 and Nanog, that plays an important role in breast CSCs [44]. Research has shown that the expression of Sox-2 in early stage of breast cancers [45]. Also, estrogen receptor $\alpha$ could regulate breast tumor-initiating cells targeting Sox-2 [46]. Our experiments demonstrated that SH down-regulated CD44 and Sox-2 expression in primary tumor specimens and metastatic lung specimens. The inhibition of CSC properties by $\mathrm{SH}$ was confirmed using in vitro mammosphere formation assay, which depends on the self-renewing ability of CSCs.

Microenvironment and cytokines related to tumor microenvironment are known to induce EMT [47]. Meanwhile, the factors play a role in the maintenance of post-EMT mesenchymal status once it is started [20]. SH is most famous for its treatment of rheumatic arthritis due to anti-inflammatory effects. In our research, when we removed organs from mouse, we found that SH decreased spleen volume and weight, especially in the 4T1 mouse model, which could be due to the partial immunosuppression of nude mice used in the MDAMB-231 mouse model. Spleen is an organ involved in the inflammation response. So we hypothesized that the inhibition effect of SH on EMT could be contributed by its inhibition on the production of inflammatory factors. IL-6 is one of the important cytokines involved in the EMT process [19] and previous studies concerning SH also demonstrated that $\mathrm{SH}$ could inhibit IL-6 [48, 49]. Our results found that SH reduced IL-6 expression in tumor specimens and lung specimens. We then used both tumor cells and macrophage cells, two of the many different sources of IL-6, to detect the effect of SH on IL-6 production in vitro. We found that $\mathrm{SH}$ decreased IL-6 production in both tumor cells MDA-MB-231 and RAW 246.7. IL-6 concentration was too low to detect in $4 \mathrm{~T} 1$ cells. This might suggest that the reduction of IL-6 expression in tumor specimens and lung specimens could be an integrated result as suppression of IL-6 secretion in both tumor cells and inflammatory cells in vivo. However, even if the inhibition effect of $\mathrm{SH}$ on both tumor cells and inflammatory cells were confirmed by in vitro experiment, the mechanism in vivo may not be as simple as it was in vitro. Il-6 is not only secreted to influence other cytokines, but also to function to influence its own production [25]. Besides, IL-6 production from tumor cells and other inflammatory cells influence each other. There were studies showing that IL-6 production from macrophage could induce IL- 6 secretion from tumor cells [50]. What's more, in the detection of MMP and 
TIMP in serum samples of mouse models, we could find secretion changes in samples from MDA-MB-231 but at a very low level which required too much samples. In contrast, in the 4T1 mouse model, we detected relatively high concentrations of MMP and TIMP. The actual total serum cytokines came from both cancer cells and mouse inflammatory cells. For the MDA-MB-231 mouse model, because we detected the production of these cytokines of human MDA-MB-231 in the mouse model and thus the human cytokines of MMP and TIMP secretion might be diluted in mouse serum. This might explain why the serum secretion was so low and suggested that the cytokines were not only come from tumor cells or host cell in vivo. All this suggested the cytokines secretion in the mouse model was a complicated process. In all, comparing with the control group, the remarkable decrease effect of SH on spleen volume and spleen weight, as well as the reduction effect of IL-6 production, indicated that SH could inhibit breast cancer metastasis by suppressing EMT and CSC which was due to the anti-inflammation effect such as IL-6.

Although more studies focusing on the anti-cancer effect of $\mathrm{SH}$ need to be done, this research gives us a new sight into the clinically used drug $\mathrm{SH}$ beyond its normal anti-rheumatic arthritis effect, helping us to uncover more potential anti-cancer effects of $\mathrm{SH}$.

\section{MATERIALS AND METHODS}

\section{Drug and agents}

$\mathrm{SH}$ was obtained from Zhengqing Pharmaceutical Group (Hunan, China). SH was dissolved in Dulbecco's modified Eagle's medium (DMEM) at $10 \mu \mathrm{mol} / \mathrm{mL}$ and filtered using $0.22 \mu \mathrm{m}$ sterile filters (Millipore). Matrigel was purchased from BD Bioscience (Pasadena, CA, USA). Transwell chambers with $8 \mu \mathrm{m}$ pore polycarbonate membrane filters (Corning, NY, USA) were used to explore the migration and invasion ability of 4T1 and MDA-MB-231 cells in response to SH. The ELISA kits of MMP-2 (CSB-E04676m for mouse; CSB-E04675h for human), MMP-9 (CSB-E08007m for mouse; CSBE08006h for human), TIMP-1 (CSB-E08004m for mouse; CSB-E08003h for human), TIMP-2 (CSB-E07387m for mouse; CSB-E04733h for human) and IL-6 (CSBE04639m for mouse; CSB-E04638h for human) were bought from Cusabio biotech (Wuhan, China).

The antibodies against E-cadherin, N-cadherin and Vimentin were obtained from Cell Signaling Technology (Beverly, MA, USA). The antibodies against MMP9, TIMP-1, TIMP-2, Sox-2, $\beta$-actin and horse-radish peroxidase (HRP) conjugated anti-rabbit or mouse IgG were purchased from Santa Cruz Biotechnology (Santa Cruz, CA, USA). The antibodies for IL-6 and CD44 were bought from Abcom Biotechnology (Cambridge, MA, USA).

\section{Cell culture}

Murine breast cancer cell line 4T1, murine macrophage cell line RAW246.7, and human breast cancer cell line MDA-MB-231 were obtained from Shanghai Institute of Cell Biology (Shanghai, PR China) in the Chinese Academy of Sciences. The bioluminescent cell line MDA-MB-231-luc was obtained in our previous experiments [51]. All cell lines were cultured in DMEM supplemented with 10\% fetal bovine serum (FBS), $100 \mathrm{U} /$ $\mathrm{ml}$ penicillin and $100 \mu \mathrm{g} / \mathrm{ml}$ streptomycin and incubated at $37^{\circ} \mathrm{C}$ in an incubator with $5 \% \mathrm{CO} 2$ and saturated humidity.

\section{Wound healing assay}

Wound healing assay was performed to assess the motility of cells exposed to SH. 4T1 and MDA-MB-231 cells were seeded in 6-well plates. When cells grew up to 90-100\% confluence, the cell monolayer was scraped by a white pipette tip. Then the detached cells were washed with PBS and serum-free medium containing different concentrations of $\mathrm{SH}$ was added. Pictures were taken under an inverted microscopy (Leica, Germany) at 0, 12 and $24 \mathrm{~h}$. The percentage of inhibition was normalized as the percentage of the untreated cells $(100 \%)$.

\section{Transwell migration assay}

Briefly, a total of $1 \times 10^{5} 4 \mathrm{~T} 1$ and MDA-MB-231 cells in $200 \mu \mathrm{L}$ serum-free medium were added in the upper transwell chambers and treated with various concentrations of $\mathrm{SH}$. The lower chambers were filled with $600 \mu \mathrm{L}$ medium containing $10 \%$ FBS. After $24 \mathrm{~h}$, the non-migratory cells on the upper surface of the chambers were removed by a cotton swab and the migrated cells were fixed in 4\% paraformaldehyde and stained with $0.5 \%$ crystal violet. Then at least five randomly chosen fields were photographed under a microscope (Leica, Germany). Finally, the migrated cells were dissolved in $30 \%$ acetic acid and measured by a microplate reader (PerkinElmer, USA) at $570 \mathrm{~nm}$. The percentage of inhibition was normalized as the percentage of the untreated cells (100\%).

\section{Matrigel invasion assay}

Matrigel was diluted 1:5 with DMEM. Transwell filters were coated with $50 \mu \mathrm{l}$ the dilution. A total of $1 \times 10^{5} 4 \mathrm{~T} 1$ and MDA-MB-231 cells in $200 \mu \mathrm{L}$ serumfree medium were added in the upper chamber and treated with various concentrations of $\mathrm{SH}$. The lower chamber was filled with $600 \mu \mathrm{L}$ medium containing $10 \% \mathrm{FBS}$. After incubation for $24 \mathrm{~h}$, cells were treated the same as the procedures for the migration assay. 


\section{Mammosphere formation assay}

Mammosphere formation assay was performed as previously described [52]. Cells were treated with $\mathrm{SH}$ for $48 \mathrm{~h}$ and collected to seed into ultralow attachment plates (Corning, NY, USA) at a density of 4000 cells / well. Cells were cultured in serum-free DMEM/F12 medium supplemented with $20 \mathrm{ng} / \mathrm{ml}$ human epidermal growth factor (EGF), $10 \mathrm{ng} / \mathrm{ml}$ human basic fibroblast growth factor (bFGF), 2\% B27 supplement and 1\% N2 supplement. On day 10, the number of tumorspheres (diameter $>50 \mu \mathrm{m}$ ) in each well were evaluated using an inverted microscope.

\section{FACScan flow cytometer analysis}

Cells were seeded in 6-well plates (Corning, NY) and treated with different concentrations of SH. Then cells were collected at the indicated time. Samples of at least $1 \times 10^{6}$ cells were stained with anti-CD44-APC conjugate (103008, Biolegend) at $4{ }^{\circ} \mathrm{C}$ for $30 \mathrm{~min}$. The cells were washed 3 times and then analyzed by flow cytometry.

\section{Western blot assay}

Cells were treated with SH and lysed in RIPA. Proteins were collected and analyzed using a similar method as our previously reported study [5].

\section{Orthotopic breast tumor metastasis model}

All animal procedures were performed according to the protocol approved by the Institutional Animal Care and Use Committee at Xi'an Jiaotong University. Four-week old female Balb/c strains of mice with body weights approximately 18-20 g were obtained from and housed in the Laboratory Animal Centre of Xi'an Jiaotong University. Each mouse was injected with $1 \times 10^{5}$ 4T1 cells into the left second mammary fat pad (day 1). The mice were randomly distributed into three groups $(n=6)$ and intraperitoneally (i.p.) injected with $0.1 \mathrm{~mL}$ physiologic saline per $10 \mathrm{~g}$ body weight daily (control group) or SH at doses of 75 or $150 \mathrm{mg} / \mathrm{kg}$ of body weight, dissolved in physiologic saline (experimental groups) from the third day. Tumor sizes were measured twice or three times a week using calipers and tumor volumes were calculated according to the standard formula: width $^{2}$ * length $/ 2$ and expressed as $\mathrm{cm}^{3}$. The mice were treated for four weeks. At the end of treatment, the mice were sacrificed and the organs and tumors of the mice were collected. Lung tissues were fixed in Bouin's solution for $24 \mathrm{~h}$ and taken pictures. Spleen volumes were calculated using the formula: length*width*height and expressed as $\mathrm{cm}^{3}$. The tissues were fixed and prepared for Hematoxylin and eosin (H\&E) staining and immunohistochemistry (IHC) analysis.

\section{Experimental breast tumor metastasis model}

Four-week old female BALB/c athymic nude mice with body weights approximately $18-20 \mathrm{~g}$ were purchased from Shanghai SLAC Laboratory Animal Co. Ltd. (Shanghai, China) and housed in the Laboratory Animal Centre of Xi'an Jiaotong University. After one week's acclimation, $1 \times 10^{6}$ MDA-MB-231-luc cells in $100 \mu \mathrm{PBS}$ were injected into the tail vein of nude mice. On the day following injection, the mice were randomly assigned to three group $(n=6)$. Animals in the control group were i.p. injected with $0.1 \mathrm{~mL}$ physiologic saline per $10 \mathrm{~g}$ body weight daily and the treatment groups were injected i.p. with SH at doses of 75 or $150 \mathrm{mg} / \mathrm{kg}$ of body weight, dissolved in physiologic saline. Bioluminescence imaging (BLI) was performed weekly using luciferin and a Xenogen IVIS 2000 Luminal Imager to monitor lung metastasis for 4 weeks. Luciferin was stocked at a concentration of $15 \mathrm{mg} / \mathrm{mL}$ and was injected i.p. at a dose of $10 \mu \mathrm{L} / \mathrm{g}$ of mouse weight. Luminescence is expressed as photons/sec/ROI (region of interest). At the experimental endpoint, mice were euthanized and the organs were prepared for $\mathrm{H} \& \mathrm{E}$ staining and $\mathrm{IHC}$ analysis. For H\&E analysis, the metastatic foci area was divided into five grades and numbered 1 to 5 . The total numbers of each histologic section were added together as the index for lung or liver metastasis.

\section{IHC analysis}

IHC analysis were performed as previous [5]. The intensity of the staining was scored as 1 (negative), 2 (weakly positive), 3 (moderately positive) or 4 (strongly positve). The extent of the staining was categorized as 1 (stained cells: $1-25 \%), 2$ (26-50\%), $3(51-75 \%)$ or 4 $(76-100 \%)$ for the tissues. The final staining score was the product of the intensity and the extent scores. Five images of random fields were taken from each specimen for quantitative analysis.

\section{Statistical analysis}

All data are expressed as mean \pm standard deviation (SD) from at least three independent experiments. The differences between the control and treatment groups were compared by $t$-test or ANOVA methods. All statistical analyses were performed using (SPSS Inc., Chicago, IL, USA). $P$ values $<0.05\left(^{*}\right)$ or $<0.01\left(^{(}\right)$were considered as statistically significant.

\section{Abbreviations}

SH, sinomenine hydrochloride; EMT, epithelial to mesenchymal transition; CSC, cancer stem cell; ECM, extracellular matrix; MMP, matrix metalloproteinase; TIMP, tissue inhibitor of metalloproteases; ELISA, 
enzyme-linked immunosorbent assay; DMEM, Dulbecco's modified Eagle's medium; HRP, horse-radish peroxidase; FBS, fetal bovine serum; i.p., intraperitoneally; H\&E, hematoxylin and eosin; IHC, immunohistochemistry; SD, standard deviation.

\section{ACKNOWLEDGMENTS}

This study is supported by a grant from the National Nature Science Foundation of China (No. 81173613), a grant from Shaanxi Social Science and Technology Project (No. 2014K11-01-01-06) and a grant from the First Affiliated Hospital of Xi'an Jiaotong University (No.12ZD29).

\section{CONFLICTS OF INTEREST}

The authors declare no conflicts of interest.

\section{REFERENCES}

1. Wang Y, Fang YF, Huang WH, Zhou X, Wang MH, Zhong B, Peng DZ. Effect of sinomenine on cytokine expression of macrophages and synoviocytes in adjuvant arthritis rats. J Ethnopharmacol. 2005; 98:37-43.

2. Qian L, Xu Z, Zhang W, Wilson B, Hong JS, Flood PM. Sinomenine, a natural dextrorotatory morphinan analog, is anti-inflammatory and neuroprotective through inhibition of microglial NADPH oxidase. J Neuroinflamm. 2007; 4.

3. Lu XL, Zeng J, Chen YL, He PM, Wen MX, Ren MD, $\mathrm{Hu}$ YN, Lu GF, He SX. Sinomenine hydrochloride inhibits human hepatocellular carcinoma cell growth in vitro and in vivo: Involvement of cell cycle arrest and apoptosis induction. Int J Oncol. 2013; 42:229-238.

4. Jiang TS, Zhou LP, Zhang WL, Qu D, Xu XM, Yang Y, Li SQ. Effects of sinomenine on proliferation and apoptosis in human lung cancer cell line NCI-H460 in vitro. Mol Med Rep. 2010; 3:51-56.

5. Li X, Wang K, Ren Y, Zhang L, Tang XJ, Zhang HM, Zhao CQ, Liu PJ, Zhang JM, He JJ. MAPK signaling mediates sinomenine hydrochloride-induced human breast cancer cell death via both reactive oxygen speciesdependent and -independent pathways: an in vitro and in vivo study. Cell Death Dis. 2014; 5:e1356.

6. Siegel RL, Miller KD, Jemal A. Cancer statistics, 2016. CA Cancer J Clin. 2016; 66:7-30.

7. DeSantis C, Ma JM, Bryan L, Jemal A. Breast Cancer Statistics, 2013. CA Cancer J Clin. 2014; 64:52-62.

8. Muller V, Riethdorf S, Rack B, Janni W, Fasching PA, Solomayer E, Aktas B, Kasimir-Bauer S, Zeitz J, Pantel K, Fehm T, group Ds. Prospective evaluation of serum tissue inhibitor of metalloproteinase 1 and carbonic anhydrase IX in correlation to circulating tumor cells in patients with metastatic breast cancer. Breast Cancer Res. 2011; 13:R71.

9. Bai L, Yang HH, Hu Y, Shukla A, Ha NH, Doran A, Faraji F, Goldberger N, Lee MP, Keane T, Hunter KW. An Integrated
Genome-Wide Systems Genetics Screen for Breast Cancer Metastasis Susceptibility Genes. PLoS Genet. 2016; 12:e1005989.

10. Chaffer CL, Weinberg RA. A perspective on cancer cell metastasis. Science. 2011; 331:1559-1564.

11. Kalluri R, Weinberg RA. The basics of epithelialmesenchymal transition. J Clin Invest. 2009; 119: 1420-1428.

12. Yan C, Grimm WA, Garner WL, Qin L, Travis T, Tan N, Han YP. Epithelial to mesenchymal transition in human skin wound healing is induced by tumor necrosis factor-alpha through bone morphogenic protein-2. Am J Pathol. 2010; 176:2247-2258.

13. Brabletz T. EMT and MET in metastasis: where are the cancer stem cells? Cancer cell. 2012; 22:699-701.

14. Hou P, Zhao Y, Li Z, Yao R, Ma M, Gao Y, Zhao L, Zhang Y, Huang B, Lu J. LincRNA-ROR induces epithelialto-mesenchymal transition and contributes to breast cancer tumorigenesis and metastasis. Cell Death Dis. 2014; 5:e1287.

15. Singh A, Settleman J. EMT, cancer stem cells and drug resistance: an emerging axis of evil in the war on cancer. Oncogene. 2010; 29:4741-4751.

16. Mani SA, Guo W, Liao MJ, Eaton EN, Ayyanan A, Zhou AY, Brooks M, Reinhard F, Zhang CC, Shipitsin M, Campbell LL, Polyak K, Brisken C, et al. The epithelialmesenchymal transition generates cells with properties of stem cells. Cell. 2008; 133:704-715.

17. Abdullah LN, Chow EK. Mechanisms of chemoresistance in cancer stem cells. Clin Transl Med. 2013; 2:3.

18. Velasco-Velazquez MA, Popov VM, Lisanti MP, Pestell RG. The role of breast cancer stem cells in metastasis and therapeutic implications. Am J Pathol. 2011; 179:2-11.

19. Sullivan NJ, Sasser AK, Axel AE, Vesuna F, Raman V, Ramirez N, Oberyszyn TM, Hall BM. Interleukin-6 induces an epithelial-mesenchymal transition phenotype in human breast cancer cells. Oncogene. 2009; 28:2940-2947.

20. Scheel C, Eaton EN, Li SH, Chaffer CL, Reinhardt F, Kah KJ, Bell G, Guo W, Rubin J, Richardson AL, Weinberg RA. Paracrine and autocrine signals induce and maintain mesenchymal and stem cell states in the breast. Cell. 2011; 145:926-940.

21. Aslakson CJ, Miller FR. Selective events in the metastatic process defined by analysis of the sequential dissemination of subpopulations of a mouse mammary tumor. Cancer Res. 1992; 52:1399-1405.

22. van Zijl F, Krupitza G, Mikulits W. Initial steps of metastasis: cell invasion and endothelial transmigration. [Article in Japanese]. Mutat Res. 2011; 728:23-34.

23. Iwata H, Kobayashi S, Iwase H, Okada Y. [The expression of MMPs and TIMPs in human breast cancer tissues and importance of their balance in cancer invasion and metastasis]. Nihon Rinsho. 1995; 53:1805-1810.

24. Duffy MJ, Maguire TM, Hill A, McDermott E, O’Higgins N. Metalloproteinases: role in breast carcinogenesis, invasion and metastasis. Breast Cancer Res. 2000; 2:252-257. 
25. Scheller J, Chalaris A, Schmidt-Arras D, Rose-John S. The pro- and anti-inflammatory properties of the cytokine interleukin-6. Biochim Biophys Acta. 2011; 1813:878-888.

26. DeSantis C, Ma J, Bryan L, Jemal A. Breast cancer statistics, 2013. CA Cancer J Clin. 2014; 64:52-62.

27. Hu G, Chong RA, Yang Q, Wei Y, Blanco MA, Li F, Reiss M, Au JL, Haffty BG, Kang Y. MTDH activation by 8 q22 genomic gain promotes chemoresistance and metastasis of poor-prognosis breast cancer. Cancer cell. 2009; 15:9-20.

28. Valastyan S, Weinberg RA. Tumor metastasis: molecular insights and evolving paradigms. Cell. 2011; 147:275-292.

29. Pulaski BA, Ostrand-Rosenberg S. Mouse $4 \mathrm{~T} 1$ breast tumor model. Current protocols in immunology / edited by John E Coligan [et al]. 2001; Chapter 20:Unit 2022.

30. Teicher BA. Tumor models for efficacy determination. Mol Cancer Ther. 2006; 5:2435-2443.

31. Chiang AC, Massague J. Molecular basis of metastasis. The N Engl J Med. 2008; 359:2814-2823.

32. $\mathrm{Vu} \mathrm{TH}$, Werb Z. Matrix metalloproteinases: effectors of development and normal physiology. Genes Dev. 2000; 14:2123-2133.

33. Fassina G, Ferrari N, Brigati C, Benelli R, Santi L, Noonan DM, Albini A. Tissue inhibitors of metalloproteases: regulation and biological activities. Clin Exp Metastasis. 2000; 18:111-120.

34. Deryugina EI, Quigley JP. Matrix metalloproteinases and tumor metastasis. Cancer Metastasis Rev. 2006; 25:9-34.

35. Kim GE, Lee JS, Choi YD, Lee KH, Lee JH, Nam JH, Choi C, Kim SS, Park MH, Yoon JH, Kweon SS. Expression of matrix metalloproteinases and their inhibitors in different immunohistochemical-based molecular subtypes of breast cancer. BMC cancer. 2014; 14:959.

36. Figueira RC, Gomes LR, Neto JS, Silva FC, Silva ID, Sogayar MC. Correlation between MMPs and their inhibitors in breast cancer tumor tissue specimens and in cell lines with different metastatic potential. BMC cancer. 2009; 9:20.

37. Kang Y, Massague J. Epithelial-mesenchymal transitions: twist in development and metastasis. Cell. 2004; 118:277-279.

38. Thiery JP. Epithelial-mesenchymal transitions in tumour progression. Nat Rev Cancer. 2002; 2:442-454.

39. Yang J, Mani SA, Donaher JL, Ramaswamy S, Itzykson RA, Come C, Savagner P, Gitelman I, Richardson A, Weinberg RA. Twist, a master regulator of morphogenesis, plays an essential role in tumor metastasis. Cell. 2004; 117:927-939.

40. Bonnet D, Dick JE. Human acute myeloid leukemia is organized as a hierarchy that originates from a primitive hematopoietic cell. Nat Med. 1997; 3:730-737.
41. Al-Hajj M, Wicha MS, Benito-Hernandez A, Morrison SJ, Clarke MF. Prospective identification of tumorigenic breast cancer cells. Proc Natl Acad Sci USA. 2003; 100:3983-3988.

42. Singh SK, Hawkins C, Clarke ID, Squire JA, Bayani J, Hide T, Henkelman RM, Cusimano MD, Dirks PB. Identification of human brain tumour initiating cells. Nature. 2004; 432:396-401.

43. Liao MJ, Zhang CC, Zhou B, Zimonjic DB, Mani SA, Kaba M, Gifford A, Reinhardt F, Popescu NC, Guo W, Eaton EN, Lodish HF, Weinberg RA. Enrichment of a population of mammary gland cells that form mammospheres and have in vivo repopulating activity. Cancer Res. 2007; 67:8131-8138.

44. Nishi M, Sakai Y, Akutsu H, Nagashima Y, Quinn G, Masui S, Kimura H, Perrem K, Umezawa A, Yamamoto N, Lee SW, Ryo A. Induction of cells with cancer stem cell properties from nontumorigenic human mammary epithelial cells by defined reprogramming factors. Oncogene. 2014; 33:643-652.

45. Lengerke C, Fehm T, Kurth R, Neubauer H, Scheble V, Muller F, Schneider F, Petersen K, Wallwiener D, Kanz L, Fend F, Perner S, Bareiss PM, et al. Expression of the embryonic stem cell marker SOX2 in early-stage breast carcinoma. BMC cancer. 2011; 11:42.

46. Zhang Y, Eades G, Yao Y, Li Q, Zhou Q. Estrogen receptor alpha signaling regulates breast tumor-initiating cells by down-regulating miR-140 which targets the transcription factor SOX2. J Biol Chem. 2012; 287:41514-41522.

47. Jing Y, Han Z, Zhang S, Liu Y, Wei L. EpithelialMesenchymal Transition in tumor microenvironment. Cell Biosci. 2011; 1:29.

48. Xiong L, Yang L. Effects of alkaloid sinomenine on levels of IFN-gamma, IL-1beta, TNF-alpha and IL-6 in a rat renal allograft model. Immunotherapy. 2012; 4:785-791.

49. Tu S, Hu Y, Lu F. Effect of Sinomenine on IL-8, IL-6, IL-2 produced by peripheral blood mononuclear cells. J Tongji Med Univ. 1999; 19:257-259.

50. Li YY, Hsieh LL, Tang RP, Liao SK, Yeh KY. Interleukin-6 (IL-6) released by macrophages induces IL-6 secretion in the human colon cancer HT-29 cell line. Hum Immunol. 2009; 70:151-158.

51. Wang K, Xie SM, Ren Y, Xia HB, Zhang XW, He JJ. Establishment of a bioluminescent MDA-MB-231 cell line for human triple-negative breast cancer research. Oncol Rep. 2012; 27:1981-1989.

52. Zhang L, Li L, Jiao M, Wu D, Wu K, Li X, Zhu G, Yang L, Wang X, Hsieh JT, He D. Genistein inhibits the stemness properties of prostate cancer cells through targeting Hedgehog-Gli1 pathway. Cancer Lett. 2012; 323:48-57. 